\title{
Translation and Nonverbal Communication
}

\section{Sunetra Sholapurkar}

\begin{abstract}
$\underline{\text { Abstract }}$
Human communication is taken as an extension of self and culture. So does translation. Usually both are done through verbal medium - language; as it is comparatively easy to understand. But problem arises where the nonverbal or non-linguistic channels of communication are involved. The primary aim of this paper is to expand the notion of translation accommodating the nonverbal channels of communication not involving language in the traditional sense. Without diminishing the importance of spoken or written words I would like to contribute to a wider understanding of translation which would standout clearly in the background of translation in its totality.

The paper will explore the communicative aspect in visual art with a special focus on the Warli tribal paintings. In the process it also seeks to link language to art and culture unfolding art as a creative communication.
\end{abstract}

Key words: nonverbal, communication, language, art, painting

\section{Translation complementing communication}

The word translation has a versatile entity and involves a chain of process with difficult entities involved in it. Traditionally, translation studies has almost exclusively dealt text that are seen as verbal only, whether written or spoken, to be interpreted. However, intersemiotic translation of Roman Jakobson's typology broadens this scope by the inclusion of non-linguistic media either as a source or the target code where the modalities proposed are 'transmutation 
of signs' - 'an interpretation of verbal signs by means of signs of non verbal sign systems' and vice versa.

This makes Intersemiotic translation the most complex translation of all as it turns the meaning of one specific expression code to an entirely different one, opening multi manipulations and interpretations which should be studied within their broader sociocultural contexts, as well as their spatio-temporal location. This is so because intersemiotic translation represents a special domain of creative interpretation which involves a radical change of habits of interpretation and new forms of sign manipulation. The reason being communication here opens multiplicity of meaningfulness leading to multi-interpretations. This is where the heart of non verbal communication lies.

\section{The extra-linguistic horizon}

To understand the sort of communication that takes place in art and how it takes place, a cultural approach is needed to study as communication in art happens through the artist's creation which is an extension of his self and his surrounding environment where he lives and works and which provides him the channels through which he can communicate his visualization. His biography, his childhood experiences, adulthood, gender, class positions in society etc. which have affected his world view, what he knows and understands about the world surrounding him are all part of the process of his creative activity and influence his creation.

Translation of such text requires a certain degree of understanding. It requires nuanced understanding of the various elements which form the language of art. The translator thus has to be equipped with adequate preparation and must possess creativity 
sensitivity along with linguistic skills to be able to transcreate a text. By relating semiotics to translation three fundamental issues; the meaning of the message, the relation of the art to the creator and the viewer makes this three dimensional spiral relationship an interesting study.

In the traditional sense language forms the main component of translation, however, in the present context the art itself becomes the text for the study. The different forms of art such as music, dance, painting, literature and even architecture which are very primitive to very sophisticated models of expression and communication may appear to differ on surface level but they all have similar structure. Principle will be same but the subjects differ. To benefit from its many functions and to participate fruitfully skills and sensibilities are needed to be cultivated.

The communication which takes place here is of highly complex kind where the symbols and the symbolized are closely related to one another which is peculiar to art. The symbols here bring out the distinction between ordinary communication and aesthetic communication where the symbols are intermingled with expressive and evocative effects. All these sign and symbols together form a language for that work of art. They have an autonomous character and serve as an intermediary among the members of any one community.

Adopting the basic Saussure model (Sausuure 1974) in visual art (paintings) each motif takes the form a signifier and the signified. The work of art is therefore a sign which is supposed to mediate some suprapersonal meaning. This is different from the best known and the most common known signs-the word. There is the difference between the artistic sign and the linguistic sign. The word 
in its normal usage serves communication with an external aim to depict to some event, to describe things etc. whereas an artistic sign exist as an aesthetic object which is located in the consciousness of the whole community. Since, communication in arts is broadly the communication of feelings and emotions difficulty arises here, precisely in understanding this as these feelings which the artist leaves upon others may also be of various kinds and degrees. They may be very strong or very weak, very important or very insignificant, very bad or very good. And only if these feelings which the artist has felt match up to the level of the viewer the artist, his creation can be called successful in real sense of art. On the other hand feeling which is always considered to be private and subjective cannot be publicly verified.

\section{Warli paintings}

Warli paintings which forms the case study of this paper takes its name from an aboriginal tribe called Warli, residing in the hinterland of Maharashtra and parts of Gujarat on the fringes of the forest of the Western ghats on the Sahyadari hills.

Warlis have chosen paintings as a medium to express themselves; their knowledge. They are very subtle yet so communicative; aesthetic and different; unique and powerful- above all universal. It is not only a means of their expression but also forms their cultural identity. These paintings sharing close resemblance to the pre historic cave paintings are not just paintings in the usual sense but are very closely connected with the lives and culture of the Warli people. Their paintings act as their language of expression and communication. The paintings give an identity to the Warlis. 
With no formal education in drawing the Warlis show a remarkable expertise in using the two main principles of form and content and design. Preference of simple typically representational lines, repetition of lines, dots, circles for intensive or rhythmical purposes and usage of minimum, basic and easily available colours with no shading in the drawings and stylization of motifs to create decorative elements is the main attraction of their drawings. Apart from these the usage of space and texture adds to beauty to the drawings. The simple motifs infuse life in their drawings.

So deeply embedded is the symbol within its cultural context that mere translation of the term or explanation of its meaning is not enough to understand the true significance of the symbol to that culture. The symbols are part of an acute mode of thought that may be available only to those of that particular culture. Their paintings, simplistic in style and nature, depict life's varying emotions and thus contribute their communicative need. In their paintings they include life around them and express everything they feel and believe in. This means that it is not only the language composed of words which have the power to communicate but there are several other means also through which communication can take place. Thus, it can be said vocal language is thus only one among many possible languages or orders of languages.

\section{The Conceptual Typology}

The traditional categories of the Warlis genius presented a twoway basic conceptual typology but with the entry of commercial forces, a third category, namely, commercial paintings and has thus pushed the native conceptual typology for an expansion. The threeway typological scheme working at present among the people who draw the paintings is the following: 
- Lagna chauk (drawing on the occasion of marriage) - marriage paintings that are drawn by the women folk during marriage ceremony as a part of the ritual.

- Muthi (arrival of new rice at home) - harvest paintings drawn by the lady of the house to celebrate the arrival of rice - the material and life promoting wealth at home.

- Vyapaar - (commercial paintings) - not restricted to women, the paintings do not depict any traditional idea or ritual; rather, they show everyday activities, life scenes and the like that are included in the paintings of the above two categories.

Closely related to the Warli marriage is their art. Murals or the wall paintings are drawn within a ritual context on the occasion of a Warli marriage are called Warli paintings. These marriage murals are drawn at the brides and the bridegroom's home, the night

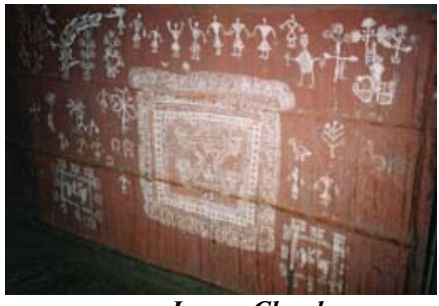

Lagna Chauk (Courtsey: Hervé Perdriolle 1998) before the actual wedding take place. The paintings are drawn on the dark wall of their inner part of their houses by the savasinis (women whose husbands are alive) and the act of painting is seen as 'writing' the chauk - (चौक लिहिणे). Therefore readings as the title in the analysis reflects tentativeness of views expressed.

The painting 'Lagna Chauk' reproduced below for the purpose of analysis is selected with an eye on the fact that a given painting should help in capturing at least one salient feature though it could afford multiple interpretations - readings. 


\section{Readings}

The immediate impression that one makes of the Warli paintings may be termed as innocence, especially as one is introduced to the images that make the paintings. As the analysis unfolds and the gaze grows more careful, along with innocence, brilliance of the forms also starts gripping. The point attains good force in the analysis that comes up to present some of the individual elements that are kept separate from the paintings. When viewed together their shapes make sense and present them as the micro forms that constitute the paintings.

A typical mind of the people that is very much rooted in the beauty of nature and celebrates every bit of it comes to the fore. In other words, it is the devoted innocence equaled with brilliance of the Warli mind that is at play in the paintings. The creative principle may be formulated as: the Warlis take an art act as a part of their act of celebration.

In the murals, that is, the wall paintings the principal area in any of these ceremonial structures, like in the one placed here, is occupied by a large square called 'chauk' or chaukat made of a series of parallel lines. The lines get extended up to larger outer square forming loops at the four corners. One of the functions, may be primary one, of the extensions is to make the joints secure.

With the discovery a flood gate to the Warli painting gets open, where all the constituting elements now stand as the makers of Warli conceptual system. The Paalghat, or call it goddess of vegetation, turns out to be the centre of the painted universe and that too with power to create, as well as, to govern the same. 
Paalghat, call it now the Mother Nature itself, at the centre of the power structure is just one dimension of it. The issue opens up into a much larger universe if it is corroborated with some of the real life discoveries among the Warlis.

For instance, once a marriage painting is painted it will have to die its natural death with the completion of an individual marriage. At the surface of it, the transitory appearance of the painting with the Paalghat at centre may be taken to mean and refer to the ephemeral side of life. But, when focused restrictedly on marriage, the painting reads as a happening and a message.

That is, as the painting surfaces on a wall, other than the decoration and the power, the Paalghat also brings along power of the plants and trees to continue through procreation and fertility of the vegetation. As if the Mother Nature is on its visit to the family and returns having blessed the family, especially the newly weds, with power to procreate.

The arrival of the Mother on the wall, sitting in the centre of the whole act, and then, vanishing like any presence turns out to be a kindest gesture into fertile continuity. After all it is life as such that invites the divine. Therefore, the family deserves the divine blessings.

The discovery should suggest that the wall paintings of the Warlis form the canvas that expresses life in its full bloom, on the one end, and the life full of celebration walks into painting, on the other.

\section{Into the Painted Universe}

When placed within the framework of Warli cosmology, as 
indicated above, the painted form of Paalghat stands out as the sign and source of fertility with cosmic power invested in it. This explains as to why the Warlis personify nature in the form of Paalghat without whom a marriage cannot take place.

Another dimension of the centrality of the Paalghat in the wall paintings in particular is linked with the Warli belief that life and death are contained within the womb of the Mother Nature, and a womb is best represented by a pot, the boundless container of life.

Thus, the Warli marriage paintings have invented a form of Paalghat goddess and make it stand for the pot overflowing with vegetation, the brimming of life. This helps the painted form to acquire symbolic significance. Fertility in the foregoing statements is a function of this symbolic power.

\section{The Mother Painted}

In its painted form Paalghat goddess is a headless figure without any physical features. This flows from the fact that anthropologically the figures are always designated. Put differently, when it comes to designation even two parallel lines with some dots on them may stand to represent a form of the divine.

It is discovered that the form goes on changing from area to area, but the fact remains that the traditional painting does not invent properly drawn head for the deity. The area differences are seen in terms of the variation in designative items.

In most of the depictions hands and legs of the Mother are spread out. To the Warlis this is just a limit of the drawn look that the form may exhibit. The form for them actually stands for a cross legged position, where the deity is in deep meditation. 


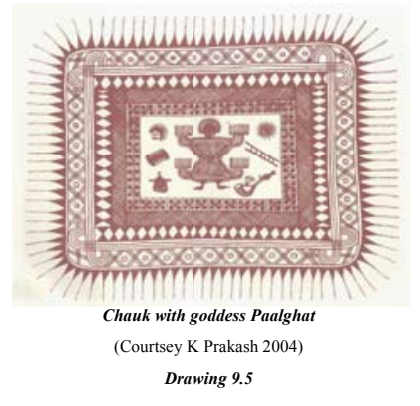

Put differently, the Mother in its painted presence on the wall does not only guide and govern the marriage that happens as she is in deep meditative self. It is even more significant in the ceremonious solemnizing of a marriage that the painting is covered so as to get the blessings of the Mother in its most sacred presence. It is not incidental that the cover is sacred among the Warlis.

The sense of the sacred governs the whole act of Warli marriage almost as a governing principle. The bride and the bridegroom are made to sit in the front of a covered painting on a wall. With the completion of marriage the painting is uncovered and the bride and the bridegroom continue to by it side.

The faith goes that the cosmic powers of the Mother present in the painting get transmitted into the being of the couple. The presence of the Mother hence comes up as the fountain source of creativity that fertilizes the living bodies.

\section{The Painted Lagna Chauk}

Lagna Chauk (marriage-chauk) is a rectangular square. It is the most striking aspect of the marriage painting. It is of paramount importance both in position it occupies with its visually striking motifs and by the fact that the entire painting is named after it.

Other than the ornamentation that it brings in with its painted form, this square also has a cosmic function in relation to the 
deity inside it, on the one hand, and to the surrounding landscape, on the other.

To the wisdom of the Warlis an act of painting is seen as 'writing' the chauk. If the idea of writing is explored to its full potential, a marriage painting among the Warlis may be seen comparable to writing of a marriage certificate in any written culture.

Originally the 'lagna chauk' consisted of twelve parallel lines. Due to elaborate ornamentation on wall, and space constraints on paper, the lines now are normally restricted to four or any even number. The count, however, has not disturbed the relationship of the lines with the Warli cosmology.

That is, even now each of the lines represents a god, who guards the universe. In each case the designated god concretizes the ancient belief that the gods preside over the four quarters of the earth and guard the universe.

From the architectural point of view, a square or a rectangle represents a house. For the Warlis the chauk represents their hut -a sense of security in the midst of the unreliable and fearful forest environment. For them, a house is not mere a place of shelter, but is as scared as their mother earth. The lagna chauk in this sense is a written document of protection or should it be said a powerful symbol of protection.

The parallel lines of the chauk consist of many designs like the circular ones called the pophalas These are half appearing concentric circles. They are present in multiples in the painting that is placed parallel to these statements. On the level of representation 
the 'pophalas' stand for three partspheres: (1) sphere of agricultural activity, where things as seeds will have to grow into crops, produce yield and be over; (2) the sphere of life where people are born, they grow and die having lived their lives; and (3) as already stated

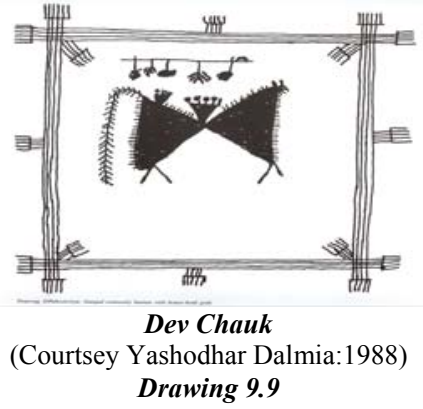
above, the sphere of painting, where a painting is painted on wall, it performs its function and is supposed to die its 'natural' death. Drawn at the time of birth and death, therefore, the painted circle symbolizes the concept of a cyclic development.

The triangles that are interpreted as temple above are used elsewhere in the Warli painting to create different designs. In some of the cases the designs, especially through form, express sexuality.

But in the triangular geometry the Warlis are unique, as they do not express sexuality in a physical sense of the term. A triangle signifies particularly the creative yoni of the Mother goddess which gives birth to life. Even in the case of intersecting triangles, called baashinga in Warli, a reading of couple in a sexual union makes sense to the Warlis only in the care of the Mother Paalghat. This turns a physical sexual act into a cosmic union in the Warli painting .

The wedding clothes and ornament designs, that are baashinga, Saakhali (series of ridges and diagonals) Paasodi (hatched parallel crosses that look more of a triangle, especially at the point of intersection) through their design and significance in a painting seems to stand as a formal translate of the actual act in Warli life. In the same way the Warli genius explores musical 
instruments also to create materials for its painting. Out of a small range of instruments Dhaak and Gangali (instruments played during marriage ceremony) are the ones that are very commonly used as the material base to create the forms in the paintings.

\section{The Chauk as a Composition}

The Warlis claim that the chauk is a vanity box of the goddess. That is why it has jewellery, a comb, an oil-bottle, a lamp, a ladder, a tarpa and the rest - all that she may need for a wedding. The sun and the moon are also seen together on the either sides of the goddess. In other words, the whole and possibly the best of the cosmos is at the call of the Mother goddess.

The space below the image of the goddess in a chauk is often seen decorated. It is normally a row of five cattles (bulls) called 'taangad' with the two shepherds, 'bombyaa' in front and 'hakyaa' at the back that form a straight line at the bottom in most of the paintings. Various trees are also there to provide shade to the goddess.

Seen from the point of view of the Warli cosmology, the small 'dev chauk' is drawn for the five-headed male god called Panchashiriya, who is shown riding the horse and whose duty is to guard and protect the mother goddess.

As in life, similarly in the painting various trees and the animals found in the vicinity of the dwellings of the warlis with which the Warlis share the space form an integral part of the painting. Apart from the trees and animals with which the Warlis share the space, a varied range of human activity like groups of men climbing the toddy plant to extract toddy, the surawallas (toddy 
carriers), turewallas (the playing band), the karavali (water carriers), the gorkya and all humble people of the community, whose services are recognized and given definite place in the Warli paintings. Dayto-day activities are also drawn to articulate celebration of marriage in these paintings. There are, for instance, men and women dancing in various formations. It is life as such that celebrates.

\section{The Colours - the materials and the codes}

The basic colour of the surface on which a Warli painting is drawn comes either from cow dung, or from red soil. That is why the two colours act as the base. This also makes the Warli painting as a coded extension of the nature.

Since the Warli paintings are done with the minimal colours that too that are locally made with the materials found in nature, the colours have deep association with the emotions of the people.

Traditionally the colours that are made at home include white, yellow and red. White is made of pounded rice; red is made from red flowers; and yellow is drawn from turmeric. Among the three colours, white is the prime colour and is used to draw the whole painting - yellow and red are mainly used to create dots.

Understood in terms of associations, the rice colour, that is white, stands in the honour of the rice goddess, Kansari. This makes the rice colour represent divine purity in these paintings. Put in terms of the Warli cosmology, the rice colour has a basic protective function. The Mother goddess, Paalghat, the sacred circles and the chauk is drawn with it protects the marriage couple from the evil spirits. 
Traditionally the dots drawn with turmeric yellow were restricted to animal drawings. May be this was due to their understanding of the white surface. In recent painting distribution of the turmeric yellow is more open and covers almost every possible figure including goddesses. This could be attributed to the broadening of the colour vision of the Warlis.

The turmeric yellow has alchemic side also. That is it has powerful antiseptic qualities. In this sense the Warlis encode their alchemic wisdom through the yellow dots, where the dots act as weapons of fighting against evil. Should it be said that there is nothing innocent about the Warli paintings? The turmeric yellow also resembles the colour of ripe corn fields. In that it is the colour of brimming fullness and ripeness.

The red kumkum or sindur which is put along with turmeric is the colour of blood. This blood is believed to be the hymeneal blood which leads to recreation. The colour can be thus associated with sexuality which could be life generative.

The Warli painting in general has developed a good inventory of forms and figures that make a painting to begin with. This helps the painting to represent reality expressed in any of the three types mentioned in the beginning of the chapter. These forms may be further classified into general types, namely, (1) humans, (2) animals, (3) birds, and (4) trees and flowers. The four types are exemplified below though with very limited details.

\section{The Enlivenment of the Painted}

The act of drawing the painting for the Warlis is just a material part of the whole process of painting. An even more 
important aspect of it is what may be called enlivenment of it. That is, once the painting is done, it is made to go through a simple though ritualistic covering.

The painting is supposed to attain magical powers in the process and is thought to be fully potent to serve and bless a marriage. The enlivenment grows into a cycle after the ritual of marriage, as the painting is left to die its natural death. To the vision of Dalmia (1988: 143) the painting does "animating the Warlis with life" during it cycle of enlivenment.

That is, the art forms that make the Warli paintings are integral part of all that they use to celebrate important occasions. These mini forms together with the paintings, the mega objects that they constitute, therefore, may be termed as a 'celebrative(s)' The creative principle offered above is confirmed as an observer participates in any of the celebrations of the Warlis.

\section{The Life-Painting Link}

Over and above the stated discoveries, the discovered code may also explain as to why Warli paintings express the rites, rituals, beliefs and now commercial interests of the Warli people. After all it is not just the mind that expresses, rather, it is the life as such that earns and celebrates.

The link between the life and the painting surfaces more of in absolute terms as it is realized that 'chauk' on the real life wall also acts as canvas. That now Warlis have started drawing chauk even on paper is an extension of the traditional form. The skill is grown so much that change in the surface does not make any big difference to the Warli hand. The link should suggest that the 
paintings may be studied as the manifest forms of all that Warlis do, draw and believe. It is the same creative mind that speaks, acts and draws in their total life. Even though the ritual paintings are still restricted to women, the commercial type of the paintings has opened up the field for the skills of everyone. The suggested link among life, mind and painting is evidently on the rise. It seems reasonable to claim that Warli paintings make a unique art form that is directly rooted through the life and culture of the Warlis. Since culture stands for the ways of life, it makes sense to see the roots of the painting in the Warli life itself.

\section{Discussion}

The above analysis suggests that communication in art cannot be based on The Information Theory or The Mathematical Theory of Communication developed by Claude Shannon et.al (1948) and other related theories which may have been very influential in communication studies and in the usual transmission of messages which are mechanical in nature where, what is sought to be communicated is clearly visualized and formulated before the process of communication is set afoot. As this notion fails in the case of art.

Human beings communicate for practical requirements, moral purposes and aesthetic experiences. One of the limitations of these theories is being unable to incorporate the creative dimension of art, at both ends - that of message creation and that of message reception.

One possible way to use its skeleton is to go to something called art as creative communication which was proposed by a Russian scholar named P.B. Ivanov who talks instead of elliptic 
communication, in which culture plays an important role in the encoding or decoding process. He makes the important point that a work of art is not conveying already existing meaning. In the communication of art there need not be and often is not such a prior understanding as a base. Hence, there need not be an expectation, in fact cannot be an expectation that the viewer will perceive the work in anyway similar to what the artist intended.

What Ivanov does not address is the fact that the artist himself in the act of creation of the painting is discovering something that may have been hidden from him before and does not really come to know until after the painting is done. Thus, the process is in short quite unpredictable because in the act of creation he is not really creating or transmitting a message for someone else. He transmits a message only in the act of putting it out for others to see and this is indeed why it consummates in the artist's delight of discovering himself in his work.

The other terrain of the paper lies in showing that communication as a process started much before words came into existence. It is argued, for instance, that among the various art forms of tribal wall paintings like Warli Painting are worth considering as the oldest medium of communication that has played a vital role in the progress of man in many ways. The timelessness of this art form, the universal language they speak through their drawings, and the unbroken continuity of their dynamic tradition reflect the lifelong struggle, genius and unparalleled vision of the people who draw these paintings.

\section{Conclusion}

Art communication has usually been seen from the artist's 
end suggesting what he intended to convey. Any work of art cannot be understood totally in its first confrontation as the viewer may not become aware of all the formal implications. However, subsequent and deeper viewing may provide clues for a fuller meaning.

But one has to take into the account the difficulties arising at the receiving end. For the meaning of a work of art or its communication potential is never exhausted as it retains its openness to ever new and fresh ways of responding to it. Communication in art is based on window opening into multiplicity of meaningfulness leading to multi-interpretations. This is where the heart of art communication lies, because the element of multi-interpretation is very delicately connected with the experience of beauty. The timelessness of art and the universal language they speak gives a multi dimensional aspect to art which distinguishes it from an ordinary communication.

So, every work of art is an autonomous sign composed of:

- A perceivable signifier; created by the artist (language).

- An aesthetic object which is registered in the collective consciousness and which functions as significance (culture).

- A relationship which refers to the total context of social phenomena (context).

This holds for the Warlis and their uniqueness as well. One may just add in all humility that the present study is just an innocent step towards the care. Hopefully, the analysis should help to conclude that Warli paintings communicate collective joy and happiness, passion and mystery, their relation, dedication and reverence to nature, their deep seeded traditions - in short their existence. 


\section{REFERENCES}

Burbank, John and Peter Steiner (ed.) 1978. Structure, Sign and Function: Selected Essays by Jan Mukarovsky. New Haven, Yale University Press.

Carey, J. W. 1992. Communication as Culture: Essays on Media and Society. New York, Routledge.

Dewey, John 2005. Art as Experience. Notes (1934). New York, The Berkeley Publishing Group.

Greenberg, J.H. 1971. Language, Culture and Communication. California, Stanford University Press.

Jhanji, Rekha 1984. Communication and the Arts. Delhi, Ajanta Publications

Leifer, Walter (ed.) 1972. Man and Art. Munchen, Germany Max Hueber Verlag.

Rangila, Ranjit Singh Sep 2004. The Sacred Invented. A National Seminar On Semiotics of the Sacred and Structures of Celebration, Central Institute of Indian Languages, Mysore.

Bethers, Ray 1963. The Language of Paintings: Form and Content. New York, Pitman Publishing Corporation.

Calliborn, Edward Booth and Daniele Baroni. 1980. The Language of Graphics. London, Thames \& Hudson. 9-32

Collingwood, R.G. 1938. The Principles $f$ Art. London, Oxford University Press.

Mukarovsky, Jan 1976. Art as Semiotic Fact, In Matejka Ladislav and Irwin R Titunik (ed.). Semiotics of Art. Cambridge, MIT Press.

Oei, Loan and Cecile De Kegel (2002). The Elements of Design : Rediscovering colours, textures, forms and shapes. London, Thames \& Hudon. 